\title{
Competition between farmed and wild fish: the French sea bass and sea bream markets
}

\author{
Esther REGNIER* $\quad$ Basak BAYRAMOGLU ${ }^{\dagger}$
}

May 30, 2014

\begin{abstract}
Aquaculture is contributing at an increasing rate to world seafood supply. The interaction between fisheries and aquaculture is especially important for the seafood market where supply of wild and farmed fish can affect price dynamics. We examine market interactions in the French fresh sea bass and sea bream markets. We test for long term price parity between farmed and wild products for these two species, applying a bivariate cointegration approach to market delineation. We also conduct the Law of One Price (LOP) test between price series. Our data base consists of monthly domestic price series for fish purchased by French households from 2007 to 2012. Our empirical results show that the fresh fish markets for whole wild and farmed sea bream are partially integrated, while those for whole wild and farmed sea bass are not integrated. The substantially higher price for wild sea bass relative to farmed sea bass suggests that consumers may be more sensitive to seafood production processes in higher-value species.
\end{abstract}

Keywords: Market interactions; Sea bass; Sea bream; Farmed fish; Wild fish JEL classification: C32; Q22

\footnotetext{
*Université Paris 1 \& Paris School of Economics, 106-112 boulevard de L'Hôpital, 75647 Paris Cedex 13, France. E-mail: esther.regnier@univ-paris1.fr.

${ }^{\dagger}$ INRA, UMR 210 Economie Publique, F-78850 Thiverval-Grignon, France. Tel: (0)1 308145 35, E-mail: Basak.Bayramoglu@grignon.inra.fr. AgroParisTech, UMR 210 Economie Publique, F-78850 Thiverval-Grignon, France.
} 


\section{Introduction}

Worldwide, an important share of marine fish stocks is under threat. Worm et al. (2009) report that $63 \%$ of assessed fish stocks worldwide require rebuilding. FAO (2012) reports that about $57.4 \%$ of world marine fish stocks are estimated as fully exploited and $29.9 \%$ as overexploited. While marine fish production has been marked by a slight decline since the early 1990s, since the early 1980s, aquaculture has been the fastest growing food industry, with annual average growth of 8.8\% (FAO, 2012). In 2010, aquaculture provided nearly $50 \%$ of global seafood ${ }^{1}$ production. "With the increasing contribution from aquaculture to seafood supply the interactions between fisheries and aquaculture are expected to become even more important and therefore deserve exhaustive investigations from socio-economic and biological perspectives" (Natale et al., 2013, p. 205). These interactions are especially important at the food market where competition between wild and farmed fish species affects fish price dynamics. ${ }^{2}$ The international trade in fish products also plays a significant role in the evolution of fish prices, given that fish and fishery products are among the most intensively traded food commodities worldwide (World Trade Organization). ${ }^{3}$ Among agricultural, food, animal and fish products, fish was one of the fastest growing categories between 1990 and 2000, with an increase of $52 \%$ in trade value (Anderson, 2003). These observations prompted our investigation of whether the expansion in global supply of farmed fish has affected the price of certain wild species consumed in France.

Information on market interactions between farmed and wild fish provides insights into the extent to which farmed fish prices are likely to affect wild fish prices. These outcomes depend on how consumers perceive wild versus farmed products, but also on the relative cost competitiveness and production quantities of each sector. For instance, farmed fish species regarded as low-value products relative to their wild counterparts, might lead to segmented markets where wild products occupy the high-value segment. This increases the pressure on wild edible resources. On the other hand, if a farmed fish is valued atleast as much as its wild counterpart, the prosperity of the capture fishery sector will rely on its relative price competitiveness.

Since aquaculture takes place in confined area (ponds, pen nets, cages, raceways, ranching, recircu-

\footnotetext{
${ }^{1}$ Understood as finfish and shellfish production.

${ }^{2}$ The interactions between fisheries and aquaculture exist also at the biological level since marine fisheries provide inputs to aquaculture production, i.e. fishmeal and fish oil. These types of interactions are beyond the scope of the present paper.

${ }^{3}$ http://www.wto.org/english/res_e/reser_e/ersd201003_e.htm.
} 
lating systems, etc.), this production technology exerts a high degree of control over the attributes of the grown fish. Consumer preferences may determine color, size, texture, fat content and other parameters that make the delivered product more convenient (Asche et al., 2001). Similarly, Knapp et al. (2007) argue that farming has changed the timing of the supply which no longer is necessarily seasonal, and show that the increased availability of farmed salmon has led to increased demand. Sustainability concerns may be another reason for a shift in preference from wild fish to farmed fish. On the other hand, wild products are perceived as healthier, and sometime more tasty, and aquaculture raises environmental concerns which provide some competitive advantage to wild products (Natale et al., 2013).

In turn, the valuation of farmed fish can condition the technological evolution of the aquaculture sector and affect the manner in which wild fish resources are managed. Indeed, the aquaculture sector strives to find solutions to the limited availability of fishmeal and fish oil ${ }^{4}$, which are required inputs to sustain the flesh properties of several farmed species. To date, there is no protein source that simultaneously provides the required properties and is profitable. However, consumers depreciating the modification of fish diet and the subsequent change in flesh nutritive quality, gives incentives to the aquaculture industry to work out a suitable substitute to natural fish populations. The aquaculture supply may be split across high-quality and low-quality supply - the latter relying on cheaper and nutritionally poorer feed. Also, if the willingness of consumers to pay for highquality farmed fish is significant, the management of fishery resources used for feed, and of species biologically dependent on them, might be enhanced or revised. Finally, public response to farming practices and their environmental impact may influence the development of this production sector.

Our aim is to examine whether the fish production process is a significant attribute in consumers' fish consumption choices, compared to species type or presentation (cut versus whole). We test for market integration between farmed and wild products in France, focusing on the cases of sea bass and sea bream species. Market integration is an indicator of the degree to which different markets are related to each other. Our empirical approach relies on the Law of One Price (LOP) and the concept of cointegration which consists of testing for price parity between wild and farmed fish products. Our data are domestic (monthly) price series provided by Kantar WorldPanel ${ }^{5}$ for a number of fish species consumed by French households from 2007 to 2012.

\footnotetext{
${ }^{4}$ Fishmeal and fish oil are derived from small oily fish belonging to low trophic levels. Farmers purchase fishmeal and fish oil in the form of compounded feed pellets providing nutrients and different supplements to farmed fish.

${ }^{5}$ Kantar WorldPanel: www.kantarworldpanel.com.
} 
The importance of the sea bass and sea bream markets at European level makes a study of these species interesting. The European Union (EU) is the largest single world market for imported fish and fishery products (FAO, 2012). After Atlantic salmon, sea bass and sea bream together represent the largest production of farmed species in Europe (FEAP, 2013), with aquaculture the main method used for their production. The EU accounts for two-thirds of world aquaculture production of sea bass and sea bream, followed by Egypt in the case of farmed sea bass, and Turkey in the case of sea bream. Intra-EU trade of these species is substantial, with Greece a major exporter of sea bass to Italy, the UK and France, and sea bream to Italy, Portugal and France. With the exception of sea bream imports from Turkey, trade between the EU and third countries is limited. Although most sea bass comes from aquaculture, capture fisheries account for more than $10 \%$ of total sea bass production worldwide. The EU accounts for: $83 \%$ of world sea bass capture, with France accounting for $60 \%$ of this total; and $32 \%$ of the world sea bream capture, with France and Spain together accounting for $74 \%$ of this total (EC DG for Maritime Affairs and Fisheries, 2009).

France is a good case to analyse market interactions between farmed and wild sea bass and sea bream products. It is a major market, the 5th biggest importer of fish and fishery products in the world, and the 2nd in Europe after Spain (FAO, 2012). For sea bass and sea bream, it is the third intra-EU importer of farmed fish, while the extent of its domestic catch satisfies national consumption of wild and farmed sea bass and sea bream. As will be discussed later, some $50 \%$ of French consumption of sea bass and around $70 \%$ of sea bream are farmed.

Market interactions between fisheries and aquaculture have been investigated from a theoretical and empirical point of view. The theoretical findings indicate that the effects of aquaculture development on fish stock and welfare depend on the degree of substitution between wild and farmed species and on the management regime. Anderson (1985) shows that in the context of a fishery with open access that is exploited beyond the maximum sustainable yield, entry of aquaculture increases total fish supply, and thus, reduces pressure on wild fish stock through a lower consumer price. Similarly, Ye and Beddington (1996) find positive social benefits from aquaculture entry but to a lesser extent when considering wild and farmed fish as imperfect substitutes with positive cross-price elasticities. Valderrama and Anderson (2010) show how limited-entry fishery regulation enables successful rent extraction relative to open access but that the decrease in price resulting from the increased supply of farmed fish dissipates these rents. 
There are numerous fish-specific and country-specific studies examining which fish attributes influence consumer choice. Many of these studies focus on salmon, and use the concept of cointegration to analyze market integration among different species and different geographic areas, or to test whether consumers distinguish between the origin, form or production process of fish products (Gordon et al., 1993; Asche and Sebulonsen, 1998; Asche et al., 1999; Clayton and Gordon, 1999; Asche, 2000; Jaffry et al., 2001; Asche et al., 2005). In the case of salmon, several studies report a highly integrated market for wild and farmed products (Asche et al., 2001; Asche et al., 2005; Knapp et al., 2007) and a relatively integrated market has been demonstrated for white fish (Asche et al., 2002 and Nielsen, 2005) and some other fish species (Nielsen et al., 2007; Norman-Lopez, 2009). Salmon generally does not compete with big volume whitefish species. The evidence on market integration seems to indicate that "farmed species competes mainly with the same wild species (and other species in the same segment), but not with other species" (Asche et al., 2001, p.311).

In the case of sea bass and sea bream, empirical analysis is scarce (Asche et al., 2001), despite the considerable trade flows they generate in the EU. To our knowledge, only two studies investigate market integration between wild and farmed sea bass and sea bream. Asche and Steen (1998) find that sea bass and sea bream "may compete with portion trout and several white fish species within the EU" (Asche et al., 2001, p. 311). Brigante and Lem (2001) find no evidence of a price link between farmed and wild species in the case of sea bass and sea bream in the Italian market. In contrast, we find that, in France, there is a partial market integration between fresh whole wild and farmed sea bream although this does not apply to fresh whole sea bass.

The present paper contributes to the literature on market interactions between wild and farmed products in the sea bass and sea bream markets. In addition to within-species interactions, we also examine how farmed and wild fish interact across species. Finally, we check whether the form of the product (whole versus cut) influences the outcomes of the market integration analysis. The empirical analysis employs a bivariate cointegration framework and we conduct a LOP test for these fish species to check whether their markets are perfectly integrated.

The rest of the paper is organized as follows. Section 2 describes the main characteristics of the French sea bass and sea bream markets. Section 3 presents the data and descriptive statistics. Section 4 presents the econometric methodology, Section 5 provides the estimation results and Section 6 discuses the outcomes of the empirical analysis. Section 7 concludes with some remarks 


\begin{tabular}{l|l|l|l|l}
\hline Sea bass $($ in tons) & $\mathbf{2 0 0 8}$ & $\mathbf{2 0 0 9}$ & $\mathbf{2 0 1 0}$ & $\mathbf{2 0 1 1}$ \\
\hline Wild production & 3279 & 5566 & 6129 & 5535 \\
\hline Farmed production & 4163 & 2877 & 2337 & 2452 \\
\hline Imports & 4525.3 & 4906.5 & 5507.1 & 5626.2 \\
\hline Exports & 3869.7 & 2974.3 & 2831.1 & 2597.5 \\
\hline Consumption & 8097.6 & 10375.2 & 11142 & 11015.7 \\
\hline Data source: Eurostat.
\end{tabular}

Table 1: French consumption of sea bass in tons

\begin{tabular}{l|l|l|l|l}
\hline Sea bream $($ in tons) & $\mathbf{2 0 0 8}$ & $\mathbf{2 0 0 9}$ & $\mathbf{2 0 1 0}$ & $\mathbf{2 0 1 1}$ \\
\hline Wild production & 2795 & 5285 & 5725 & 5126 \\
\hline Farmed production & 1182 & 1278 & 1239 & 1412 \\
\hline Imports & 8340.2 & 9474.5 & 9055.4 & 8461.9 \\
\hline Exports & 1784 & 1973.6 & 1925.8 & 1622.2 \\
\hline Consumption & 10533.2 & 14063.9 & 14093.6 & 13377.7 \\
\hline Data source: Eurostat.
\end{tabular}

Table 2: French consumption of sea bream in tons

on the potential competition between fresh farmed and wild products in the French sea bass and sea bream markets.

\section{The French sea bass and sea bream markets}

Sea bass is a demersal white fish which originates in the Eastern Atlantic, and the Mediterranean and Black Seas. France, the UK, Italy, Turkey and Egypt have significant sea bass fisheries. Sea bream is also a demersal white fish found in the Atlantic Ocean and the Mediterranean sea, but commercial harvests are small.

Tables ?? and ?? infer from trade flows annual French consumption of sea bass and sea bream, in volume, between 2008 and 2011. The data refer to all types/forms of product (frozen, canned, filleted, whole, etc.) and all varieties of sea bass and sea bream species. In 2008-2011, average total French consumption of sea bass was 10,157.6 tons compared to 13,017 tons for sea bream. French catches of sea bass represent about $50.5 \%$ of national consumption against $36.4 \%$ for sea bream.

French aquaculture production is not expected to increase due to land ownership and legal issues that restrict availability of sites. Both species studied are increasingly supplied by aquaculture operations, mostly in the Mediterranean Sea. The rapid expansion in the production of these 
species in the early 1990s was driven by increased aquaculture in Turkey and Greece. Juveniles are produced on increasingly large scales in hatcheries, and availability is no longer a constraint on the industry. Since domestic aquaculture production is limited in France, any consumption rise has to be covered by imports (FAO Globefish, 2009).

Among fresh finfish household consumption - excluding the catering sector — in 2011, sea bass is ranked 7 th in value $(€ 63,547 \mathrm{k})$ and 6 th in volume $(4,563$ tons), and sea bream is ranked 9 th in value $(€ 51,145 \mathrm{k})$ and 7 th in volume $(4,534$ tons). The highest ranked species for value and volume are salmon and cod. These figures combine wild and farmed fish consumption. The values in brackets represent the value of total consumer purchases of a given species in France in 2011, estimated by FranceAgriMer based on Kantar WorldPanel data.

According to these figures and to FranceAgriMer (2011), about 50\% of French consumption of sea bass and $70 \%$ of French consumption of sea bream is farmed. ${ }^{6}$

\section{The data set}

Our data set is provided by Kantar WorldPanel. ${ }^{7}$ It reports aggregate monthly home consumption of fresh fish in a sample of French households. The time series data cover the period January 2007 to September 2012 (69 points). The category fresh products includes products sold by large retailers, supermarkets, fishmongers, markets and grocery stores. The analysis does not include other product forms (i.e. transformed products, frozen or canned fish consumption) since Kantar WorldPanel data do not distinguish between farmed and wild for these product types.

Our empirical analysis focuses on sea bass and sea bream fish species ${ }^{8}$, for which we have information on fish-specific quantities consumed (in $\mathrm{kg}$ ), fish-specific prices (euros $/ \mathrm{kg}$ ), production mode (farmed/wild) and form (whole/cut).

\footnotetext{
${ }^{6}$ It was not possible to obtain the share of wild and farmed fish within the national imports and export figures of each species.

${ }^{7}$ Kantar WorldPanel: www.kantarworldpanel.com.

${ }^{8}$ There are several varieties of sea bass and sea bream species, which are aggregated in our time series data. The sea bass and sea bream varieties included in our study and their main capture zones (source: FishBase) are: sea bass species Dicentrarchus labrax (Eastern Atlantic, Mediterranean and Black Sea) and Anarhichas lupus (Northeast Atlantic, Northwest Atlantic, Baltic Sea and Northwestern Mediterranean) - the only farmed species is Dicentrarchus labrax sea bass; sea bream species Sparus aurata (Northeast Atlantic, northern Mediterranean and Black Sea), Spondyliosoma cantharus(Eastern Atlantic, Mediterranean and the Black Sea), Pagellus bogaraveo (Eastern Atlantic and Western Mediterranean), Coryphaena hippurus (Atlantic, Indian and Pacific), Sebastes mentella (Western and Eastern Atlantic), Sebastes marinus (Western and Eastern Atlantic) and Lithognathus mormyrus (Eastern Atlantic, Mediterranean, Western Indian Ocean) - the main farmed species is Sparus aurata.
} 
Fresh products constitute 33.3\% of household seafood expenditures (FranceAgriMer, 2011). Since farmed fish are sold mostly in fresh products forms (EC DG for Maritime Affairs and Fisheries, 2009), this data set provides a good base for investigating market integration between farmed and wild fish species. Moreover, commercial catches of sea bass and sea bream, which are the focus of this study, are mainly sold fresh.

The French household sample surveyed by Kantar WorldPanel is updated weekly and includes 20,000 households assumed to be representative of the French population (based on demographic criteria defined by INSEE). Within the sample, the yearly respondent replacement ratio is $25 \%$. About 12,000 of the surveyed households declare non-bar coded fish product purchases, that is, fresh fish products. We focus on this data subset. Note that only species for which at least $2 \%$ of households are buyers are considered as significant and recorded by Kantar WorldPanel. Kantar surveys are based on voluntary declarations by households. Therefore, Kantar WorldPanel measures of aquatic product purchases by French households are not exhaustive. Taking all fish and fish products together, this panel is estimated to represent $80 \%$ of total French seafood consumption (FranceAgriMer, 2011).

The data set shows that, on average, over the period January 2007 to September 2012, 31.3\% of fresh sea bass and $40.5 \%$ of fresh sea bream consumed by households in France is farmed. Between 2007 and 2012, we observe a shift in the share of farmed sea bass consumption from $27.13 \%$ to $36.5 \%$, while the share of sea bream remained steady at around $40 \%$. Since the available time series are for household consumption of fresh sea bass and sea bream, it is inevitable that these figures will not match the figures for total national consumption, that is, $50 \%$ for farmed sea bass and $70 \%$ for farmed sea bream. Yet, the difference is not negligible. Furthermore, since the Kantar WorldPanel data set is based on households' consumption recollection, for $20 \%$ of fresh sea bass consumption reported, the distinction farmed/wild is not available, compared with $30 \%$ for fresh sea bream. However, this does not represent a limit on our empirical analysis since the methodology only requires information on the price of seafood products to test for market integration.

Detailed consumption statistics are reported in Table 3. Farmed products are presumably consumed whole rather than cut for both species type. We focus our analysis on whole products rather than cut forms since $63.4 \%$ of fresh sea bass and $80.3 \%$ of fresh sea bream are sold whole. These figures are in line with the 2004 report for the European Commission (Roth and Ukendt, 2004) on sea bass and sea bream markets which states that both species are mostly sold as whole fish. 
Moreover, in the case of both species, commercial catches are mainly sold fresh and whole to local markets.

\begin{tabular}{l|l|l|l|l}
\hline \multirow{2}{*}{} & \multicolumn{2}{|c|}{ Sea bass } & \multicolumn{2}{c}{ Sea bream } \\
\cline { 2 - 5 } & whole & cut & whole & cut \\
\hline farmed & 84381.3 & 17050.2 & 117560.8 & 13445.4 \\
$\mathbf{( \% )}$ & $(39.2)$ & $(17.88)$ & $(44.68)$ & $(4.8)$ \\
\hline wild & 134104.7 & 75059.8 & 144309.6 & 38197.9 \\
$\mathbf{( \% )}$ & $(60.8)$ & $(82.12)$ & $(55.82)$ & $(95.2)$ \\
\hline Total & 218486 & 92110 & 261870.4 & 51643.3 \\
$(\mathbf{\%})$ & $(100)$ & $(100)$ & $(100)$ & $(100)$ \\
\hline Quantities in kg. \\
Data source: Kantar WorldPanel. \\
\hline
\end{tabular}

Table 3: Average share of fresh sea bass and sea bream consumption in France by product type: January 2007-September 2012

\subsection{Descriptive statistics}

Table 4 presents the average prices of fresh sea bass and sea bream, by product form and production process, consumed between January 2007 and September 2012 by the French households included in our data set. To enable a market delineation approach, price series have been deflated using the OECD monthly consumer price index for food (base year 2005). The sea bass price is $€ 12.55 / \mathrm{kg}$ and the sea bream price is $€ 9.93 / \mathrm{kg}$ over our observation period. Hence, sea bass is a higher-valued species relative to sea bream. Cut products are always more expensive since price is affected by the cost of labor. Also, the price per $\mathrm{kg}$ of whole fish is discounted by the weight of waste (bones, skin, etc.).

\begin{tabular}{|c|c|c|c|c|}
\hline & \multicolumn{2}{|c|}{ Sea bass } & \multicolumn{2}{|c|}{ Sea brean } \\
\hline & farmed & wild & farmed & wild \\
\hline whole & $\begin{array}{l}9.28 \\
(0.13)\end{array}$ & $\begin{array}{l}14.24 \\
(0.18)\end{array}$ & $\begin{array}{l}8.29 \\
(0.12)\end{array}$ & $\begin{array}{l}10.3 \\
(0.15)\end{array}$ \\
\hline cut & $\begin{array}{l}13.18 \\
(0.33)\end{array}$ & $\begin{array}{l}14.29 \\
(0.22)\end{array}$ & $\begin{array}{l}11.26 \\
(0.31)\end{array}$ & $\begin{array}{l}13.9 \\
(0.19)\end{array}$ \\
\hline average & 10.6 & 14.26 & 8.59 & 11.02 \\
\hline
\end{tabular}

Table 4: Average price of fresh sea bass and sea bream in France by product type: January 2007-September 2012

Wild products always have higher economic value. Focusing on the whole product form, the mean 
price of wild sea bass is statistically higher than that of farmed sea bass, at the $5 \%$ level (see Table ?? in Appendix ??). This holds also for sea bream (see Table ?? in Appendix ??). The price difference between the wild and farmed products is $54 \%$ for sea bass against $24 \%$ for sea bream.

With the exception of salmon whose market story is rather unique and where consumers favor the reliable and abundant supply of farmed product (Knapp et al., 2007), the empirical evidence shows higher prices for wild compared to farmed products for given species (FranceAgriMer, 2012). In the case of salmon, the large fillets provided by the farm product it delivers allow for product differentiation and innovation, thus enlarging the consumer base for this species. In the case of sea bass and sea bream, their smaller fillet size makes marketing innovations less applicable. As already mentioned, supply of both species in the market has increased in recent years. However, the effect on market prices of this increased supply is different. Sea bream prices have fallen drastically while sea bass prices have remained stable (FAO, Globefish, 2009). Thus, some producers are suffering considerably because of reduced margins. According to the FAO, over time, markets will be able to absorb larger production volumes but more stable equilibrium prices will require more product innovation and the development of additional markets in the long run.

Figures 2 to 5 in Appendix ?? plot the different pairwise price (in log) dynamics for which we test for market integration.

\section{Empirical methodology}

\subsection{Market integration}

Stigler (1969) defines the market for a good as "the area within which the price of a good tends to uniformity, allowance being made for transportation costs". When the LOP holds, that is, when there are no opportunities for arbitrage between identical goods, markets are said to be perfectly integrated. If in the long run, the prices of identical goods differ by more than transportation costs, this is a sign of an inefficient market.

There are several studies that apply the LOP test to assess whether prices differ significantly between distant areas or across international borders. For instance, Chen and Knez (1995) develop two notions of integrated markets in the finance literature. First, perfectly integrated markets are consistent with the LOP: portfolios with similar payoffs should be assigned similar prices. 
Second, markets cannot be integrated if there are cross-market arbitrage opportunities. Broda and Weinstein (2008) compare the prices of a huge range of products with a common barcode system between Canada and the USA. One of their main findings is that, use of micro level data reveals much less deviation in the LOP in response to borders and distance, than use of aggregate data, as in Engel and Rogers (1996).

For prices in logarithms, Broad and Weinstein (2008) refer to the relative LOP, by comparing with the absolute LOP defined by Stigler (1969). In this case, the LOP tests whether a shift in the price of one good results in the same percentage variation in the price of the other good, meaning their relative price remains constant. Under the condition that variables are stationary, relative LOP can be tested by running a simple OLS regression:

$$
\ln \left(P_{1 t}\right)=B+A \ln \left(P_{2 t}\right)+\varepsilon_{t}
$$

where $P_{i t}$ is the price of good $i=1,2$, at time $t$. The coefficient $A$ corresponds to price elasticity between both goods, and $B$ is a constant term. If $A=0$, then there is no relationship between these two goods. If $A=1$, then the relative LOP holds. In the remainder of this paper, the acronym LOP refers to this relative definition.

However, time series displaying stochastic evolutions may be incidentally correlated, leading to significant coefficients although the prices of the goods under scrutiny are not related. This phenomenon produces what is commonly called a spurious regression. Several tests exist to identify the order of integration of a time series, including the Augmented Dickey-Fuller (ADF) unit root test $^{9}$ and the Kwiatkowski-Phillips-Schmidt-Shin (KPSS) test ${ }^{10}$, which we rely on in this study. The inferences from the KPSS test are complementary to those derived from the Dickey-Fuller distribution.

\subsection{The concept of cointegration as a market delineation approach}

In the event that variables are non-stationary, cointegration analysis is required to investigate the relationship between time-series. The concept of cointegration in our framework allows us to

\footnotetext{
${ }^{9}$ The appropriate critical values applying to the Augmented Dickey-Fuller test are tabulated in Engle and Yoo (1987) and McKinnon (1991).

${ }^{10}$ Critical values for the KPSS test are taken from Kwiatkowski et al. (1992).
} 
identify whether price series have similar stochastic trends and whether there is a stable long run relationship between them, revealing the existence of a price parity condition. In this case, we can infer that markets display a level of integration.

The cointegration approach to market delineation is convenient in the sense that only price series are required. The drawback is that this method provides less precise information on the relationship between markets. It can show whether two goods display constant relative prices in the long run but not the degree of substitutability between them. However, Asche et al. (1997) perform a cointegration test for market delineation and estimate a dynamic system of demand equations on the same data set. They find that both approaches provide compatible and complementary results. As mentioned in Section 3, since we do not have reliable information on quantities or household attributes, we adopt the cointegration approach to analyze market interactions between wild and farmed fish.

Consider two price variables, $p_{1 t}$ and $p_{2 t}$, where lower case letters refer to natural logarithms. Assuming $p_{1 t}$ and $p_{2 t}$ are $I(1)$, then the vector $\mathbf{p}_{\mathbf{t}}=\left(\begin{array}{l}p_{1 t} \\ p_{2 t}\end{array}\right)$ is said to be cointegrated if there exists a unique nonzero $(2 \times 1)$ vector $\boldsymbol{\beta}$, such that:

$$
z_{t}=\boldsymbol{\beta} / \mathbf{p}_{t} \rightarrow I(0)
$$

with $\boldsymbol{\beta} \boldsymbol{\prime}=[1,-\beta]$ the cointegration vector, and $z_{t}$ the residual which measures the equilibrium error.

In this bivariate context, testing for LOP consists of controlling whether the coefficients of the cointegration vector sum to zero, that is $\boldsymbol{\beta} \boldsymbol{\prime}=[1,-1]$. This can be performed by applying a likelihood-ratio test of restrictions on the parameters in $\boldsymbol{\beta}$. While cointegration identifies market boundaries, LOP specifies market inter-dependencies (Nielsen, 2005). If the pairwise cointegration test reveals a common stationary trend and the LOP test is validated, then the relative price of the goods is constant and markets are perfectly integrated. If the pairwise cointegration test reveals a common stationary trend but the test for LOP is rejected, then the markets are partially-integrated. Finally, if no common stationary trend is found, the goods belong to different markets. 


\subsection{The Johansen multivariate cointegration test}

The concept of cointegration can be generalized to $n$ variables, as long as they are $I(d)$ processes, with $d>0$. The existence of cointegration vectors requires that the linear combination of the $n$ variables is $I(d-b)$. Johansen (1988) developed a multivariate approach of cointegration based on a maximum likelihood estimator, to identify the number of cointegration relations between $n$ variables studied simultaneously. This approach appeals to a vector autoregressive (VAR) model in error correction (ECM) form (Bourbonnais, 2009):

$$
\Delta \mathbf{p}_{t}=A_{0}+B_{1} \Delta \mathbf{p}_{t-1}+B_{2} \Delta \mathbf{p}_{t-2}+\cdots+B_{l-1} \Delta \mathbf{p}_{t-l+1}+\pi \mathbf{p}_{t-1}+\varepsilon_{t}
$$

where the residual series $\varepsilon_{t} \sim i . i . d$ and they are normally distributed with mean $0, A_{0}$ a vector of dimension $(n \times 1)$, matrix $B_{i}$ are functions of matrix $A_{i}$ of dimension $(n \times n)$, and $\pi=\left(\sum_{i=1}^{l} A_{i}-I\right)$. The matrix $\pi$ can be written as $\pi=\boldsymbol{\alpha} \boldsymbol{\beta}$, where $\boldsymbol{\alpha}$ is the vector of adjustment parameters and $\boldsymbol{\beta}$ is a vector containing the coefficients of the long run relation between variables.

Each independent linear combination in $\pi$ corresponds to a cointegration vector. Thus, if the rank of matrix $\pi$ is between between 1 and $n$, then there exists $r$ cointegration relations. A rank of $\pi$ equal to $n$ implies that all variables are $I(0)$, a rank equal to 0 implies that none of the linear combinations between time series are stationary. Johansen (1995) proposes two types of tests to identify the rank of $\pi$ : the trace test and the maximal eigenvalue test. Both tests work by successively excluding hypothesis about the value of $r$. Initially, the null hypothesis $H_{0}: r=0$ is tested against $H_{0}: r>0$. If $H_{0}$ is rejected, the same alternative hypothesis is tested for $r+1$, and so on until $H_{0}$ is accepted. ${ }^{11}$

To conduct a bivariate cointegration test between the prices of wild and farmed fish, follows an explicit expression of the VECM we estimate as:

$$
\begin{aligned}
& \Delta p_{1 t}=a_{0}^{1}+b_{1}^{1} \Delta p_{1 t-1}+b_{2}^{1} \Delta p_{2 t-1}+\cdots+b_{2 l}^{1} \Delta p_{2 t-l}+\alpha^{1}\left(p_{1 t-1}-\beta p_{2 t-1}\right)+\varepsilon_{t}^{1} \\
& \Delta p_{2 t}=a_{0}^{2}+b_{1}^{2} \Delta p_{1 t-1}+b_{2}^{2} \Delta p_{2 t-1}+\cdots+b_{2 l}^{2} \Delta p_{2 t-l}+\alpha^{2}\left(p_{1 t-1}-\beta p_{2 t-1}\right)+\varepsilon_{t}^{2} .
\end{aligned}
$$

\footnotetext{
${ }^{11}$ Critical values for these tests can be found in Johansen and Juselius (1990).
} 
Table 5: ADF tests for unit roots in price series of fish

\begin{tabular}{lllll}
\hline Prices in log & $\begin{array}{c}\text { Test stat. } \\
\text { level }\end{array}$ & $\begin{array}{l}\text { Critical } \\
\text { value (5\%) }\end{array}$ & $\begin{array}{c}\text { Test stat. } \\
\text { first-diff. }\end{array}$ & $\begin{array}{c}\text { Critical } \\
\text { value ( 5\%) }\end{array}$ \\
\hline Whole farmed sea bass & 0.185 & -1.950 & $-6.046^{*}$ & -1.950 \\
Whole wild sea bass & -2.786 & -3.492 & $-4.171^{*}$ & -1.950 \\
Whole farmed sea bream & -2.691 & -2.917 & $-5.855^{*}$ & -1.950 \\
Whole wild sea bream & -0.270 & -1.950 & $-5.125^{*}$ & -1.950 \\
Cut wild sea bass & 0.186 & -1.950 & $-5.678^{*}$ & -1.950 \\
Cut wild sea bream & -2.649 & -2.918 & $-9.017^{*}$ & -1.950 \\
\hline
\end{tabular}

*Statistically significant at the $5 \%$ level.

\section{Empirical results}

\subsection{Unit root tests}

The first step in tackling market integration between goods is to examine whether price series are non-stationary in level. Table 5 reports the results of the ADF test for the price series of interest for our analysis. In each case, the test statistic in column 1 is obtained after selecting the most appropriate specification among the three models underlying the ADF test, including number of lags. For all price series, test statistics are greater than the critical values reported in column 2, implying that their exists a unit root, that is, the null hypothesis of non-stationarity is not rejected at the $5 \%$ significance level. Column 3 shows that for all price series in first-differences, the null hypothesis is rejected at the $5 \%$ significance level.

Table 6 reports the results of the KPSS test. For almost all price series, the null hypothesis of stationarity in trend is rejected at the $5 \%$ significance level. For whole farmed sea bream and cut wild sea bream, the null hypothesis is rejected at the $10 \%$ significance level. The results of the two tests converge. Evidence of non-stationarity in level, and stationarity in first-difference, allows us to conduct cointegration tests on these variables.

\subsection{Competition between wild and farmed fish within the sea bream and sea bass markets}

The results of the pairwise cointegration tests between whole wild and farmed sea bass, and whole wild and farmed sea bream are displayed in Table 7. Robustness checks for both VECM are reported in Appendix ??. The first two columns in Table 7 provide the value of the trace and 
Table 6: KPSS tests of stationarity over price series of fish

\begin{tabular}{lll}
\hline Prices in log & $\begin{array}{c}\text { Test stat. } \\
\text { level }\end{array}$ & $\begin{array}{c}\text { Test stat. } \\
\text { first-diff. }\end{array}$ \\
\hline Whole farmed sea bass & $0.207^{*}$ & .067 \\
Whole wild sea bass & $0.164^{*}$ & .036 \\
Whole farmed sea bream & $0.24^{*}$ & .056 \\
Whole wild sea bream & $0.143^{* *}$ & .023 \\
Cut wild sea bass & $0.179^{*}$ & .044 \\
Cut wild sea bream & $0.123^{* *}$ & .037 \\
\hline
\end{tabular}

Note: ${ }^{*}$ Statistically significant at the $5 \%$ level.

${ }^{* *}$ Statistically significant at the $10 \%$ level.

Critical value at the $5 \%$ level: 0.146 .

Critical value at the $10 \%$ level: 0.119 .

maximum-eigenvalue statistics for testing the null hypothesis of no cointegration vector; columns 3 and 4 report these statistics for the null hypothesis of one cointegration vector. We rely on the Akaike Information Criterion (AIC) and the Bayesian Information Criterion (BIC) to select the number of lags in explanatory variables.

Table 7: Within species bivariate Johansen tests between wild and farmed fish

\begin{tabular}{|c|c|c|c|c|c|c|}
\hline \multirow[b]{3}{*}{ Prices in $\log$ (Whole fish) } & \multirow{2}{*}{$\begin{array}{l}\text { Null } \\
\text { Rank }=0\end{array}$} & \multicolumn{3}{|l|}{ hypotheses } & \multicolumn{2}{|c|}{ LOP test } \\
\hline & & & Rank=1 & & & \\
\hline & $\begin{array}{l}\text { Trace } \\
\text { statistic }\end{array}$ & $\begin{array}{l}\text { Max-eigen. } \\
\text { statistic }\end{array}$ & $\begin{array}{l}\text { Trace } \\
\text { statistic }\end{array}$ & $\begin{array}{l}\text { Max-eigen. } \\
\text { statistic }\end{array}$ & $L R$ & $p$-value \\
\hline Sea bass: farmed/wild & 33.608 & $19.779^{* *}$ & 13.829 & 13.883 & & \\
\hline Critical value at the $1 \%$ level & $(24.60)$ & $(20.20)$ & $(12.97)$ & $(12.97)$ & & \\
\hline Sea bream: farmed/wild & 21.345 & 21.345 & $6.996^{*}$ & $6.996^{*}$ & 4.59 & 0.0322 \\
\hline Critical value at the $5 \%$ level & $(19.96)$ & $(15.67)$ & $(9.42)$ & $(9.24)$ & & \\
\hline
\end{tabular}

Note: ${ }^{*}$ Statistically significant at the $5 \%$ level. ${ }^{* *}$ Statistically significant at the $1 \%$ level.

In the case of sea bass, the trace test does not accept the null hypothesis of one cointegration between price series, while the maximum-eigenvalue test accepts the null hypothesis of no cointegration vector at the $1 \%$ significance level. This result indicates the absence of a long term price parity condition between wild and farmed sea bass. In other words, the markets for these two fish products are not integrated.

We proceed to the Gregory-Hansen residual-based test for cointegration in the presence of a regime shift, between the prices series of wild and farmed sea bass, to control for whether the cointegration relation between these prices is marked by a break. We find no evidence of cointegration. We 
conclude that neither good is treated as a substitute by consumers.

In the case of sea bream, both the trace and maximum-eigenvalue tests accept the null hypothesis of one cointegration vector at the $5 \%$ significance level. Hence, whole wild and farmed sea bream display a long run price parity condition. The last column of Table 7 reports the results of the LOP test which show that it does not hold. The null hypothesis, $H_{0}:\left[\beta_{\text {wild }}, \beta_{\text {farmed }}\right]=[1,-1]$, imposing restrictions on the long-run parameters is rejected at the $5 \%$ significance level. This means that wild and farmed sea bream markets are partially integrated (i.e., goods are imperfect substitutes).

Table 8 reports the estimate of the long-run relation between wild and farmed sea bream, normalized to the price of wild sea bream.

Table 8: Sea bream model: the estimated cointegration vector

\begin{tabular}{ll}
\hline & Coefficient \\
\hline$\beta_{\text {wild }}$ & 1 \\
$\beta_{\text {farmed }}$ & -0.232 \\
constant & -1.834 \\
\hline
\end{tabular}

\subsubsection{Testing for weak exogeneity of the wild and farmed sea bream}

The weak exogeneity test relates to the vector of adjustment parameters, $\boldsymbol{\alpha}$, of a VECM. It allows us to check whether the price of one good $p_{1 t}$, conditions the price of the other, $p_{2 t}$, or vice versa. In other words, it identifies whether the cointegration relation is led by one of the commodities. It consists of testing the null hypothesis $H_{0}: \boldsymbol{\alpha}=0$. Recall that these parameters ensure return of the system variables towards the long run equilibrium. They weight the cointegration relation in each of the model equations. If $H_{0}$ is accepted for one of the model equations, the associated dependent variable is said to be weakly exogenous.

Table 9 presents the estimates of the adjustment coefficients for the VECM between farmed and wild sea bream. The adjustment parameter labeled $\alpha_{\text {wild }}$ (resp. $\alpha_{\text {farmed }}$ ) intervenes in the equation where the dependent variable is wild sea bream (resp. farmed sea bream). We observe that $\alpha_{\text {wild }}$ is significant at the $5 \%$ level while not $\alpha_{\text {farmed }}$. These outcomes imply that the price of farmed sea bream is weakly exogenous. In other words, farmed sea bream is the price-leading production sector in the French fresh whole sea bream market. 
Table 9: Sea bream model: adjustment parameters

\begin{tabular}{llll}
\hline & Coefficient & Std. Err. & $p$-value \\
\hline$\alpha_{\text {wild }}$ & $-3.79 *$ & 0.211 & 0.000 \\
$\alpha_{\text {farmed }}$ & -0.81 & 0.169 & 0.417 \\
\hline
\end{tabular}

*Statistically significant at the $5 \%$ level.

\subsection{Competition between wild and farmed fish across different species}

Table 10 reports pairwise cointegration tests between wild and farmed fish across different species. Precisely, we test for cointegration and the LOP between farmed sea bass and wild sea bream, and between farmed sea bream and wild sea bass. The idea is to appraise how farmed sea bass and sea bream interact with some different species of wild white fish, in the French fresh fish market.

Table 10: Cross species bivariate Johansen tests between farmed and wild fish

\begin{tabular}{|c|c|c|c|c|c|c|}
\hline \multirow[b]{3}{*}{ Prices in log (Whole fish) } & Null & hypotheses & & & \multicolumn{2}{|c|}{ LOP test } \\
\hline & Rank $=0$ & & Rank $=1$ & & & \\
\hline & $\begin{array}{l}\text { Trace } \\
\text { statistic }\end{array}$ & $\begin{array}{l}\text { Max-eigen. } \\
\text { statistic }\end{array}$ & $\begin{array}{l}\text { Trace } \\
\text { statistic }\end{array}$ & $\begin{array}{l}\text { Max-eigen. } \\
\text { statistic }\end{array}$ & $L R$ & $p$-value \\
\hline Farmed sea bream/Wild sea bass & 76.428 & 57.213 & 19.215 & 19.215 & & \\
\hline Farmed sea bass/Wild sea bream & 35.69 & 26.573 & $9.118^{*}$ & $9.118^{*}$ & 0.03 & 0.8580 \\
\hline Critical value at the $5 \%$ level & $(19.96)$ & (15.67) & $(9.42)$ & $(9.24)$ & & \\
\hline
\end{tabular}

Note: ${ }^{*}$ Statistically significant at the $5 \%$ level.

Columns 3 and 4 in Table 10 report the trace and maximum-eigenvalue statistics for the null hypothesis of one cointegration vector. Not surprisingly, since the farmed sea bass price is not cointegrated with its wild counterpart, farmed sea bream is also not treated as a substitute for wild sea bass. ${ }^{12}$

However, our test results indicate that farmed sea bass and wild sea bream compete in the French fresh fish market. Both the trace and maximum-eigenvalue tests support the null hypothesis of one cointegration vector at the $5 \%$ significance level. Furthermore, the LOP holds for these two fish species.

Table 11 reports the estimate of the long-run relation between wild sea bream and farmed sea bass, normalized with respect to the price of wild sea bream. As it appears, $\beta_{\text {farmed_bass }}$ is quasi equal to 1 , thus the satisfaction of the LOP.

\footnotetext{
${ }^{12}$ We also applied the Gregory-Hansen test (1996) for cointegration with regime shifts between the prices series of farmed sea bream and wild sea bass but found no evidence of cointegration.
} 
Table 11: Farmed sea bass versus wild sea bream: the estimated cointegration vector

\begin{tabular}{ll}
\hline & Coefficient \\
\hline$\beta_{\text {wild_bream }}$ & 1 \\
$\beta_{\text {farmed_bass }}$ & -1.064 \\
constant & 0.033 \\
\hline
\end{tabular}

Table 12: Bivariate Johansen test between fish of different form

\begin{tabular}{lllll}
\hline & \multicolumn{3}{l}{ Null } & hypotheses \\
\cline { 2 - 5 } Prices in log & Rank=0 & \multicolumn{3}{l}{ Rank=1 } \\
\cline { 2 - 5 } & Trace & Max-eigen. & Trace & Max-eigen. \\
& statistic & statistic & statistic & statistic \\
\hline Whole wild bass/cut wild bass & 65.85 & 33.75 & 32.1 & 32.1 \\
Whole farmed bream/cut wild bream & 67.9 & 20.68 & 47.22 & 20.68 \\
Whole farmed bass/cut wild bream & $15.17^{*}$ & 11.66 & 3.5 & 3.5 \\
\hline
\end{tabular}

Note: *Statistically significant at the $5 \%$ level.

\subsection{Assessing the effect of product form on market integration}

We conduct additional bivariate Johansen tests in order to assess the extent to which the form of the products affects consumers' behavior. Intuition would say that purchasers of whole products have a more binding economic constraint than time constraint, compared to those purchasing cut fish, or are more familiar with fish products and more willing to take on filleting, skinning, etc.

The results in Table 12 show that cut wild and whole farmed sea bass prices are not cointegrated. The null hypothesis of one cointegration vector is not accepted by the maximum-eigenvalue and trace tests at the $5 \%$ significance level. The product form does not affect the outcome of the cointegration test between wild and farmed sea bass reported in Table 7 .

We find also that cut wild sea bream and whole farmed sea bream prices are not cointegrated. This result is different from the result for whole wild sea bream and whole farmed sea bream reported in Table 10. The third cointegration test concerns cut wild bream and whole farmed bass. The null hypothesis of no cointegration vector is significative at the $5 \%$ level according to the trace test, while the maximum-eigenvalue test does not accept the null hypothesis of one cointegration vector. This finding contrasts with the result of the bivariate Johansen test for both fish in their whole form, reported in Table 10.

Hence, the product form of the fish apparently has an impact on the outcomes of our market delineation analysis. 
Table 13: Market integration outcomes

\begin{tabular}{|l|l|l|l|}
\hline & & Whole farmed sea bream & Whole farmed sea bass \\
\hline Whole wild sea bass & not integrated & not integrated \\
\hline Whole wild sea bream & partially-integrated & perfectly-intergated \\
\hline Cut wild sea bass & & not integrated \\
\hline Cut wild sea bream & not integrated & not integrated \\
\hline & & & \\
\hline
\end{tabular}

\section{Discussion}

Table 13 summarizes the results of our market delineation analysis of sea bass and sea bream species in France.

We interpret the outcomes of the bivariate Johansen tests as follows. The existence of a cointegration relation between the price series for wild and farmed fish explains a certain degree of the substitutability between them. Indeed, since the structure of production costs of the aquaculture and fish capture industries are quite different, we consider it reasonable to assume that market integration between both fish products stems from the demand behaviour of consumers rather than spillover effects of common supply factors.

In the case of sea bass and sea bream farming, feed, juveniles and labour account for around $70 \%$ of production $\operatorname{costs}^{13}$, of which about $35 \%$ is for fish feed (Roth, and Ukendt, 2004). Feed costs are affected mainly by factors such as growth in import demand and the soybean price (FAO, Globefish, 2013). In the case of fisheries, capital investment and operational costs are the main costs. Operational costs include labour costs, running $\operatorname{costs}^{14}$ and vessel costs. In France, 80\%$90 \%$ of sea bass and sea bream catches are from trawling. Running costs represent about $30 \%$ of demersal fish trawlers' total costs (FAO, 2005).

In the absence of cointegration between two price series, we do not rule out the possibility that the demand for each product interacts. We consider that supply side characteristics may account for this outcome.

Precisely, in a competitive market, if consumers consider wild and farmed fish of the same species as perfect substitutes, then both product prices should equalize (allowance being made for transportation costs), otherwise the less competitive sector would be ousted. If prices do not equalize,

\footnotetext{
${ }^{13}$ Fuel and energy consumption represents about $1 \%$ of total costs in Greece against $6 \%$ in France. Typically, this expense is for running seawater pumps, oxygenation and other machinery, vehicles, boats and refrigeration plant.

${ }^{14}$ Running costs are principally fuel, lubricants, harbour dues, cost of ice, food and supplies for the crew.
} 
this might mean that both commodities are imperfect substitutes, which does not preclude the possibility of a price parity condition. If no price parity condition is found then either the farmed and wild fish are not substitutes, or the wild and farmed sea bass markets are not efficient.

Asche et al. (2001) argue that the relative market share of each type of product is important for price adjustment mechanisms. That is, there needs to be good availability of each product to enable consumer arbitrage between both product types.

\section{The fresh whole sea bream market}

We find that the whole farmed and wild sea bream markets are partially integrated, and that their price relationship is led by farmed sea bream (Table 7).

Based on the difference in the costs of aquaculture and capture fishery, we can conclude that these products display a certain degree of substitutability. Partially integrated markets mean that whole wild and farmed sea bream are imperfect substitutes. The wild fish benefits from a price premium (survey average price: $€ 10.3 / \mathrm{kg}$ against $€ 8.29 / \mathrm{kg}$ ), indicating a relatively higher willingness to pay for this product. However, the fact that whole farmed sea bream is the price leader suggests that whole wild sea bream may incur a downward price pressure. Whether consumer perception of farmed products evolves positively or negatively will determine the price competitiveness of the fishery sector, and in turn, its economic viability. The positive consequence of downward pressure on the wild sea bream price is that it may reduce pressure on sea bream stocks, allowing supply to increase. It may also push fisheries to undertake an economic rationalization of the industry. In these respects, and as is generally the case, market competition benefits the consumer.

However, fishermen rarely target a single species. The lower profitability of sea bream due to strong price competition from the aquaculture sector may lead fishermen to report fishing pressure on other fish species within their catch bundles. Although aquaculture production may alleviate pressure on a given wild species, it is not possible to qualify and quantify the net effect of farming on ecosystem sustainability owing to the numerous linkages among species.

\section{The fresh whole sea bass market}

The empirical results in Table 7 indicate that wild and farmed sea bass markets are not integrated. Markets for fresh sea bass and sea bream differ in that: (1) wild sea bass is valued higher than 
wild sea bream on average; (2) the price differential between wild and farmed sea bass is more important, than that between wild and farmed sea bream; (3) the market shares of wild versus farmed fish are better balanced in the case of sea bream.

It is not obvious whether the absence of cointegration between farmed and wild sea bass relates to consumers' sensitivity to the fish production process in the case of higher-value species, or to supply features which may prevent market interactions between the fish. Below, we propose several arguments to explain this result.

The data described in Section 3 show that the average share of farmed sea bass in French households' consumption between 2007 and 2012, is 31.3\% (all forms of the product included). Assuming our quantity figures are accurate, we posit that this share could be reasonably considered sufficient to regard the market interaction between fresh farmed and wild sea bass as effective. Yet the share of farmed fish in household consumption of whole sea bass increases over the period, meaning that the balance between farmed and wild sea bass has improved recently. The monthly price series covering January 2007 to September 2012 might be too short to reveal market integration between these two fish products. Further, the supply of farmed and wild sea bream, whose price series are cointegrated, is more balanced (i.e. $40.5 \%$ of fresh sea bream consumed by households in France is farmed over our observation period).

In the event that market inefficiencies, such as the absence of trade-off opportunities at a finer regional scale, account for the absence of market integration between wild and farmed sea bass, the high price difference between whole wild and farmed sea bass likely reflects, inter alia, the higher production costs of the capture fishery sector compared to the aquaculture industry.

On the other hand, suppose the supply of fresh whole farmed and wild sea bass is efficient, the absence of market integration between both fish means that the production process prevails over species type in the consumer's purchasing decision. Actually, production process produces a separation in the French whole sea bass market, with wild fish occupying the high-value segment.

Based on our empirical analysis, the higher-value of sea bass compared to sea bream (survey average price, including all fish forms and production process: $€ 12.55 / \mathrm{kg}$ against $€ 9.93 / \mathrm{kg}$ ) does not produce the same price relation between wild and farmed fish for each species (i.e. no market integration versus partial-market integration). This difference can be explained by consumers that purchase lower value fish are less discerning about flesh property. If this is the case, the results 
of our analysis are in line with Natale et al. (2013) who argue that interactions between wild and farmed products are likely to become more common, particularly in lower price aquaculture segments, as the production of newer aquaculture species expands to a level capable of conditioning the market.

\section{Cross species market integration}

We test also for how farmed sea bass and sea bream interact with wild sea bream and sea bass, respectively (Table 10). These species are white fish species and have similar flesh appearance. Sea bass meat is pinkish when raw and opaque white when cooked. Sea bream meat is also rosecolored when raw and turns white when cooked. Both fish have the same average size. Since we are considering whole products, this attribute matters. Average sea bass length is $50 \mathrm{~cm}$; average sea bream length is $30-45 \mathrm{~cm}^{15}$ (FishBase).

As expected, the empirical results in Table 10 show that fresh whole farmed sea bream and wild sea bass price series are not cointegrated. These fish display even higher price differences than whole wild and farmed sea bass. The price differential is not, on its own, an impediment to substitutability on its own. Yet, as wild and farmed sea bass are not cointegrated (Table 7), it is even less likely that wild bass and farmed bream, which differ by species type as well as production process be cointegrated.

Our empirical results show also that whole farmed sea bass and wild sea bream do compete in the French fresh whole fish market. Specifically, we find that the markets for these two products are perfectly integrated. This result is quite surprising since wild and farmed whole sea bream markets are only partially integrated. However, referring to Table 4, over our survey period the average price of whole wild sea bream $(€ 10.3 / \mathrm{kg})$ is closer to the price of whole farmed sea bass $(€ 9.28 / \mathrm{kg})$ than to the price of whole farmed sea bream $(€ 8.29 / \mathrm{kg})$. According to this cross species result, the argument that would seem to prevail in relation to consumer arbitrage is that what matters in the lower-value fresh fish market segment, is the price consumers are willing to pay to consume fresh fish rather than the production process or species type.

\footnotetext{
${ }^{15}$ Note that these figures refer to wild fish length which is the only measure available.
} 


\section{The product form attribute}

Table 12 controls for whether the fish form (cut/whole) is a determinant of the consumption decision. Similar to the analysis of both fish in their whole forms (Table 7), we find that the market for cut wild and whole farmed sea bass is not integrated. This finding is not surprising given that the price differential between cut wild sea bass and whole farmed sea bass is slightly greater than that between both fish in their whole form (average wild price is higher: $54 \%$ against $53 \%)$.

In contrast, the markets for cut wild bream and whole farmed bream are not integrated, so as those of cut wild bream and whole farmed bass, although both pairwise cointegration tests yield opposite results when considering fish in their whole forms (Table 7 and Table 10). Again, the price differential between cut wild sea bream and whole farmed sea bream is greater than that between both fish in their whole form (average wild price is higher: $67.7 \%$ against $24.3 \%$ ). This also holds for cut wild bream and whole farmed bass (average wild price is higher: $49.8 \%$ against $11 \%)$.

Therefore, the product form affects market integration outcomes at least for the species considered in our analysis in their fresh form. The price premium and the gain in preparation time provided by cut fish apparently outweigh other product attributes.

We showed that in the case of whole sea bream, the production process is not an impediment to substitutability between fish that are imperfect substitutes. In the case of whole wild sea bream and whole farmed bass, neither species type nor production process is a binding criterion for substitutability between these fish products. Common to these cointegration relationships is that they refer to fish priced at below $€ 10 / \mathrm{kg}$ on average.

\section{Conclusion}

In this study, we tested for price parity between farmed and wild fish, in their whole form, in the French fresh sea bass and sea bream markets. We applied a bivariate cointegration framework to conduct our empirical analysis. We also conducted the Law of One Price (LOP) test between price series in order to check whether the markets were perfectly integrated. Our data provide monthly domestic price series for fish purchased by French households from 2007 to 2012. 
Our main empirical results show that the fresh fish markets for whole wild and farmed sea bream are partially integrated but the markets for whole wild and farmed sea bass are not. The substantially higher price of wild sea bass relative to farmed sea bass, suggests that consumers may be more sensitive to the seafood production process in the case of higher-value species. In contrast, in the case of whole sea bream, the production process does not prevent fish substitutability, although imperfect. In addition, species type is not an obstacle to market integration between wild and farmed products, given the substitutability of whole wild sea bream and whole farmed bass. These results suggest that for fish products under a certain price (i.e., around $€ 10 / \mathrm{kg}$ ), economic constraints seem to be the main deciding criteria when purchasing fresh white fish.

This study used aggregated data for the case of France. This does not account for spatial heterogenity in consumption patterns and marine captures. The report to the European Commission points out "Geographical market preferences can be identified within countries. For example seabass consumption is moderate in Western regions of France and Paris and seabream consumption is concentrated along the Mediterranean and the Western coast." (Roth and Ukendt, 2004, p.57). Testing for fish price parity between the different regions in France would require explicit spatial data.

Acknowledgments. The authors acknowledge the support of the French National Research Agency (ANR) under the CLEANER project (ANR-NT09-505778).

\section{References}

[1] Anderson, J. L., (1985). Market interactions between aquaculture and the common-property commercial fishery, Marine Resource Economics, Vol. 2(1), 1-24.

[2] Anderson, J. L., (2003). The International Seafood Trade, Cambridge: Woodhead Publishing.

[3] Asche, F., Salvanes, K. G. and Steen, F., (1997). Market delineation and demand structure, American Journal of Agricultural Economics, Vol. 79(1), 139-150.

[4] Asche, F. and Sebulonsen, T., (1998). Salmon prices in France and the UK: Does origin or market place matter?, Aquaculture Economics $\mathscr{E}$ Management, Vol. 2(1), 23-30. 
[5] Asche, F. and Steen, F., (1998). The EU - one or several fish markets: an aggregated market delineation study of the EU fish market, SNF-Report 61/98.

[6] Asche, F., Bremnes, H. and Wessells, C. R., (1999). Product aggregation, market Integration, and relationships between prices: An application to world salmon markets, American Journal of Agricultural Economics, Vol. 81(3), 568-581.

[7] Asche, F., (2001). Testing the effect of an anti-dumping duty: the US salmon market, Empirical Economics, Vol. 26(2), 343-355.

[8] Asche, F., Bjorndal, T. and Young, J., (2001): Market interactions for aquaculture products, Aquaculture Economics $\&$ Management, Vol. 5(5-6), 303-318.

[9] Asche, F., Gordon, D. V. and Hannesson, R., (2002): Searching for price parity in the European whitefish market, Applied Economics, Vol. 34(8), 1017-1024(8).

[10] Asche, F., Guttormsen, A. G., Sebulonsen, T. and Sissener, E. H., (2005). Competition between farmed and wild salmon: the Japanese salmon market, Agricultural Economics, Vol. 33, 333-340.

[11] Bourbonnais, R. Econométrie, $7^{e}$ édition Dunod, Paris, 2009.

[12] Brigante, R. and Lem, A., (2001). Price interaction between aquaculture and fishery, Working paper, XIII EAFE Conference, Salerno, April 2001.

[13] Broda, C. and Weinstein D. E.,(2008) Understanding International Price Differences Using Barcode Data, NBER Working Paper No. 14017.

[14] Chen, P. and Knez, P.J., (1995) Measurement of market integration and arbitrage, The Review of Financial Studies, Vol. 8(2), 287-325.

[15] Clayton, P. L. and Gordon, D. V., (1999). From Atlantic to Pacific: price links in the US wild and farmed salmon market, Aquaculture Economics 83 Management, 3(2), 93-104.

[16] Engel, C. and Rogers, J. H., (1996). How Wide Is the Border?, American Economic Review, Vol. 86(5), 1112-1125.

[17] Engle, R. F. and Yoo, S., (1987). Forecasting and Testing in Cointegrated Systems, Journal of Econometrics, Vol. 35 (1), 143-159. 
[18] [European Commission Directorate-General for Maritime Affairs and Fisheries], (2009). Study on the Supply and Marketing of Fishery and Aquaculture Products in the European Union, Executive Summary.

[19] [FAO], (2005). Economic Performance and Fishing Efficiency of Marine Capture Fisheries, FAO Fisheries Technical paper 482.

[20] [FAO], (2012). The State of World Fisheries and Aquaculture, Fisheries and Aquaculture Department.

[21] [FAO GLOBEFISH], (2009). Seabass and Seabream, European Price report: http://www.globefish.org/seabass-and-seabream-market-reports.html.

[22] [FAO GLOBEFISH], (2013). Fish oil and Fish meal, European Price report: http://www.globefish.org/fish-oil-and-fishmeal-january-2013.html.

[23] [FEAP], (2013). European Aquaculture Production Report 2003-2012, Federation of European Aquaculture Producers.

[24] [FranceAgriMer], (2011). Consommation des Produits de la Pêche et de l'Aquaculture. Les données statistiques de FranceAgriMer 2012 / PECHE ET AQUACULTURE.

[25] [FranceAgriMer], (2011). La Commercialisation et la Consommation des Produits Aquacoles, Focus sur le bar et la dorade royale. LES SYNTHESES de FranceAgriMer 2011 / PECHE ET AQUACULTURE.

[26] [FranceAgriMer], (2012). Les produits de la Pêche et de la Pisciculture en France, Dossier de Presse.

[27] Gordon, D. V., (1993) A Fish Is a Fish Is a Fish? Testing for Market Linkages on the Paris Fish Market. Marine Resource Economics, Vol. 8, 331-343.

[28] Jaffry, S., Pascoe, S., Taylor, G., and Zabala, U., (2000). Price interactions between salmon and wild caught fish species on the Spanish market, Aquaculture Economics 83 Management, Vol. 4(3/4), 157-167.

[29] Johansen, S., (1988). Statistical Analysis of Cointegration Vectors, Journal of Economic Dynamics and Control, Vol. 12, 231-254. 
[30] Johansen, S. and Juselius, K., (1990). Maximum Likelihood Estimator and Inferences on Cointegration with Application to the Demand for Money, Oxford Bulletin of Economics and Statistics, Vol. 52(2), 169-201.

[31] Johansen, S., (1995). Likelihood-based inference in cointegrated vector autoregressive models, Oxford University Press.

[32] Knapp, G., Roheim, C. A., and Anderson, J. L., (2007). The great salmon run: competition between wild and farmed salmon, TRAFFIC North America, Washington D.C.: World Wildlife Fund.

[33] Kwiatkowski, D., Phillips, P. C. B., Schmidt, P., Shin, Y. (1992). Testing the null hypothesis of stationarity against the alternative of a unit root, Journal of Econometrics, Vol. $54(1-3), 159-178$.

[34] McKinnon, J. G., (1991). Critical Values for Cointegration Tests, in Engle R. F. and Granger, C. W. J. (eds), Long-run Econometrics and Statistics, Oxford University Press, 267-276.

[35] Natale, F., Hofherr, J., Gianluca, F., Virtanen, J. (2013). Interactions between aquaculture and fisheries, Marine Policy, Vol. 38, 205-213.

[36] Nielsen, M., (2005). Price formation and market integration on the European first-hand market for whitefish, Marine Resource Economics, Vol. 20, 185-202.

[37] Nielsen, M., Setala, J., Laitinen, J., Saarni, K., Virtanen, J. and Honkanen, A., (2007). Market integration of farmed trout in Germany, Marine Resource Economics, Vol. $22,195-213$.

[38] Norman-Lopez, A., (2009). Competition between different farmed and wild species: the US Tilapia market, Marine Resource Economics, Vol. 24, 237-251.

[39] [OECD], (2010). Advancing the Aquaculture Agenda, Workshop Proceedings.

[40] Stigler, G.J. (1969). The Theory of Price, London, England: MacMillan.

[41] Roth, E. and Ukendt, M., (2004). Study of the market for aquaculture produced seabass and seabream species. The European Commission DG Fisheries, Final Report 23rd April 2004. Department of Marketing. 
[42] Valderrama, D. and Anderson, J., (2010). Market interactions between aquaculture and common-property fisheries: Recent evidence from the Bristol Bay sockeye salmon fishery in Alaska, Journal of Environmental Economics and Management, Vol. 59, 115-128.

[43] Ye, Y. and Beddington, J. R., (1996). Bioeconomic interactions between the capture fishery and aquaculture, Marine Resource Economics, Vol. 11, 105-123.

[44] Worm, B., Hilborn, R., Baum, J. K., Branch, T. A., Collie, J. S., Costello, C., Fogarty, M. J., Fulton, E. A., Hutchings, J. A., Jennings, S., Jensen, O. P., Lotze, H. K., Mace, P. M., McClanahan, T. R., Minto, C., Palumbi, S. R., Parma, A. M., Ricard, D., Rosenberg, A. A., Watson, R., Zeller, D., (2009). Rebuilding Global Fisheries, Science, Vol. 325, 578-585. 